\title{
Nitro-Carbazole Based Oxime Esters as Dual Photo/Thermal Initiators for 3D Printing and Composite Preparation
}

Shaohui Liu ${ }^{1,2}$, Bernadette Graff ${ }^{1,2}, \mathrm{Pu} \mathrm{Xiao}^{3 *}$, Frédéric Dumur $^{4 *}$, Jacques Lalevée ${ }^{1,2 *}$

${ }^{1}$ Université de Haute-Alsace, CNRS, IS2M UMR 7361, F-68100 Mulhouse, France

${ }^{2}$ Université de Strasbourg, France

${ }^{3}$ Research School of Chemistry, Australian National University, Canberra, ACT 2601, Australia

${ }^{4}$ Aix Marseille Univ, CNRS, ICR UMR 7273, F-13397 Marseille, France

*Corresponding authors: pu.xiao@anu.edu.au; frederic.dumur@univ-amu.fr; jacques.lalevee@uha.fr

Abstract: A series of Type I photoinitiators (PIs) based on the nitrocarbazole scaffold have been developed and examined for the first time as photoinitiators for visible light photopolymerization. Three oxime esters (OXE-M, OXE-V, OXE-P) varying by the terminal groups (acetyl, acryloyl and benzoyl) attached via the oxime ester group were originally prepared. Favorable molar absorption coefficients were found at $405 \mathrm{~nm}$ for these PIs due to the presence of the nitro group attached to the carbazole chromophore. As a result of this, the three PIs exhibited excellent photoinitiation abilities in the presence of acrylate monomers upon LED@ 405 nm irradiation. Markedly, OXE-M exhibited a better performance than the benchmark Type I phosphine-oxide (diphenyl(2,4,6-trimethylbenzoyl)phosphine oxide TPO). Chemical mechanisms supporting the polymerization process with these PIs were investigated by steady state photolysis, molecular orbital calculations and real-time Fourier transformed infrared spectroscopy. After the cleavage of $\mathrm{N}-\mathrm{O}$ bond and decarboxylation, free radicals are generated to initiate the free radical polymerization efficiently. Free radical photopolymerization of OXE-M was applied in direct laser write and 3D printing. Interestingly, OXE-M exhibited thermal initiation behaviors in monomers and can be used as dual photo and thermal initiators. The highly opaque feature of carbon fibers 
makes it difficult for light penetration, so dual photo/thermal curing are used here to prepare carbon fiber composites.

Keywords: Photoinitiator, oxime esters, 3D printing; dual cure systems

In recent decades, photopolymerization has received an increasing attention due to its numerous advantages such as a spatial and temporal controllability, no emission of volatile organic compounds and low energy consumption. ${ }^{1,2}$ This polymerization technique has been successfully applied in many fields including conventional industries (e.g. ink, adhesive) and many cutting-edge technologies (e.g. 3D-4D printing, microelectronic processing etc). ${ }^{3-7}$ Light-emitting diodes (LEDs) demonstrate many distinct advantages over traditional UV irradiation sources such as security, low cost and longer emission wavelengths. In recent years, near UV and visible LEDs have been widely used in scientific research and industrial production. ${ }^{8}$ Indeed, LEDs exhibit a tremendous potential as an alternative to the UV irradiation sources. ${ }^{9,10}$ In photoinitiating systems, photoinitiator (PI) is a vital component which can generate active species capable to initiate polymerization under light irradiation. At present, a portion of commercial PIs (e.g. hydroxyl ketones, benzophenones) can only be activated under UV irradiation. ${ }^{11-13}$ Therefore, the development of new PIs which could be used under near UV and visible LEDs irradiation is significant. ${ }^{14,15}$

A large number of photoinitiating systems activable upon LED irradiation have been designed, but most of them contain two or three components usually based on the organic chromophore/onium salt/amine combinations. ${ }^{16,17}$ The performance of these multicomponent systems is easily influenced by the solubility, the electron transfer efficiency or the viscosity of the resins that can adversely affect the efficacy of the different bimolecular interactions. Therefore, it is important to develop unimolecular photoinitiating systems where these different parameters have not to be considered anymore. ${ }^{18}$ Type I PIs which are excited and generate active free radicals by the cleavage of chemical bonds have efficient photoinitiation ability for free radical polymerization. While most of the Type I PIs are sensitive in the UV range, a few PIs 
such as 2-benzyl-2-(dimethylamino)-1-[4-(4-morpholinyl) phenyl]-1-butanone (369) and phosphine-oxides such as diphenyl(2,4,6-trimethylbenzoyl)phosphine oxide (TPO) can be activated upon excitation at $405 \mathrm{~nm}$.

As efficient Type I PIs, oxime esters (OXEs) have attracted a wide attention due to their high photoreactivity. ${ }^{19-22}$ Generally, OXEs undergo the cleavage of N-O bond to produce iminyl and acyloxy radicals in excited states (depending of the chemical structures, cleavage from singlet or triplet state can be expected). ${ }^{23}$ Then, decarboxylation reactions occur in acyloxy radicals accompanied by the generation of $\mathrm{CO}_{2}$. Commercial PIs such as $O$-benzoyl- $\alpha$-oxooxime OXE01 and $O$-acetyloxime OXE02 have been successfully applied to the production of polymer films in color filter resists. $^{24,25}$ The maximum absorption wavelength is $326 \mathrm{~nm}$ and $338 \mathrm{~nm}$ for OXE01 and OXE02 respectively, and the light absorption is almost transparent for wavelength $\lambda>400 \mathrm{~nm}$. Unfavorable conversions of methyl methacrylate were notably reported in the presence of OXE01 and OXE02 upon irradiation at $405 \mathrm{~nm} .^{23}$ Therefore, the performances of OXE01 and OXE02 under near UV and visible LED irradiation are too poor to satisfy the demands of application.

In the present study, three oxime ester PIs (OXE-M, OXE-V, OXE-P) and the same chromophore without the oxime-ester functionality (OXE-H) were designed and synthesized. In these OXEs, a nitro-carbazole group is selected as the chromophore due to the good light absorption properties in the near-UV/visible range. As far as we know, there is no report about OXEs based on nitro-carbazole chromophores. The structures of these photoinitiators and other compounds used in this study are shown in Scheme 1. The synthesis and characterizations of the different products are given in the Supporting Information. The photoinitiation ability and photoactivity of the different derivatives was studied and the application in $3 \mathrm{D}$ printing experiments were also carried out. OXEs are applied as PI normally. In this study, we propose a new series of OXEs which could be used in dual photo/thermal curing. The thermal stability and thermal initiator behavior of these OXEs were evaluated via differential scanning calorimetry (DSC). Markedly, these OXEs can be used as dual (photo and thermal) initiators for the 
preparation of carbon fiber composite.

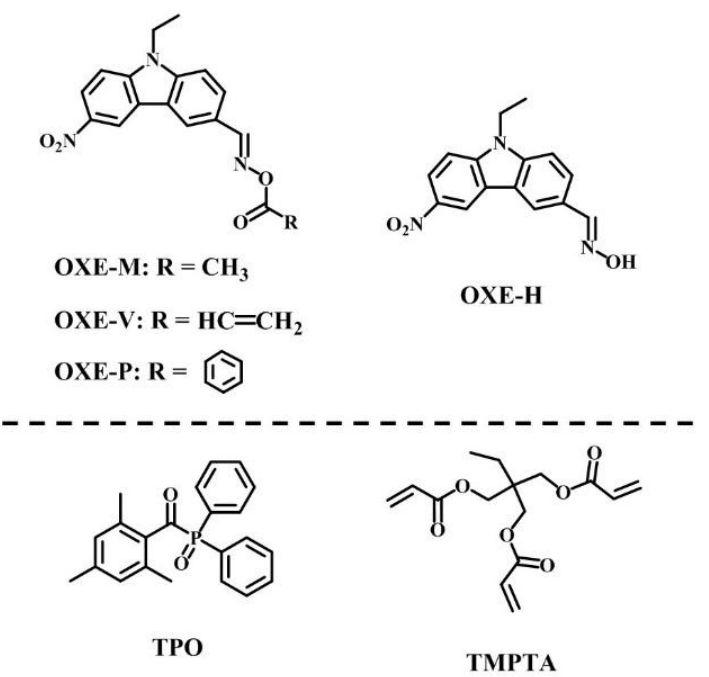

Scheme 1. Chemical structures of oxime esters and other compounds investigated in this study.

UV-visible absorption spectra of the different PIs in acetonitrile are shown in Figure 1a and the light absorption characteristics of each molecule are given in the Table $\mathrm{S} 1$. The maximum absorption wavelength $\left(\lambda_{\max }\right)$ of OXE-H is located at $376 \mathrm{~nm}$. Upon introduction of the oxime ester functionality, the $\lambda_{\max }$ of OXEs are slightly blue-shifted compared to that of OXE-H and the molar extinction coefficients at maximum absorption wavelength $\left(\varepsilon_{\max }\right)$ are increasing. The $\varepsilon_{\max }$ of OXE-P $\left(13800 \mathrm{M}^{-1} \mathrm{~cm}^{-1}\right)$ is higher than that of OXE-M $\left(13000 \mathrm{M}^{-1} \mathrm{~cm}^{-1}\right)$ and OXE-V $\left(12400 \mathrm{M}^{-1} \mathrm{~cm}^{-1}\right)$. The molar extinction coefficients at $405 \mathrm{~nm}\left(\varepsilon_{405} \mathrm{~nm}\right)$ for OXE-M, OXE-V and OXE-P are 4100, 3900 and $4100 \mathrm{M}^{-1} \mathrm{~cm}^{-1}$ respectively (much better than for the benchmark TPO). The light absorption properties of these OXEs support their application as photoinitiators at $405 \mathrm{~nm}$.

Molecular orbital calculations on the optimized geometries are depicted in Figure 1b. Both the highest occupied molecular orbital (HOMO) and the lowest unoccupied molecular orbital (LUMO) are strongly delocalized with a strong participation of the nitro group and a $\pi-\pi^{*}$ charge transfer transition is observed. The HOMO and LUMO of OXEs are mainly located on the nitro-carbazole and the oxime ester moieties rather 
than the substituents on the terminal moieties of oxime ester group. Therefore, the substituents have only a slight effect on the $\lambda_{\max }$ of OXEs which is in full agreement with the UV-visible absorption spectra.

To investigate the photochemical reactions of these OXEs, steady state photolysis experiments were carried out at room temperature. The UV-visible absorption spectra of OXEs in acetonitrile were measured upon LED@405 nm irradiation at different times. As shown in Figure 1c, the absorbance of OXE-M at $\varepsilon_{\max }=369 \mathrm{~nm}$ decreased obviously after irradiation. It is attributed to the cleavage of the N-O bond. Meanwhile, new products were formed by photolysis fragmentation, so that the maximum absorption wavelength was blue-shifted. No clear isosbestic points were found due to the further dissociation of the primary products. OXE-V and OXE-P systems exhibited the same photolysis behaviors (See Figure S1). This phenomenon was also observed in other reports. $^{24}$

Different from other Type I PIs, OXEs undergo the decarboxylation upon irradiation normally. The generated $\mathrm{CO}_{2}$ was detected by RT-FTIR. The infrared spectra of OXE-M system in the polymerization processes at $\mathrm{t}=0 \mathrm{~s}$ and $\mathrm{t}=30 \mathrm{~s}$ are presented in the Figure 1d. Obviously, a new absorption peak at $2337 \mathrm{~cm}^{-1}$ appears after irradiation and it was assigned to $\mathrm{CO}_{2} \cdot{ }^{26,27}$ Besides, the new absorption peaks were also observed in OXE-V and OXE-P systems, while it was not found in acyl phosphine oxide PI TPO and OXE-H (without the oxime-ester functionality) systems (Figure S2). It thus demonstrates the generation of $\mathrm{CO}_{2}$ for OXEs under irradiation. 

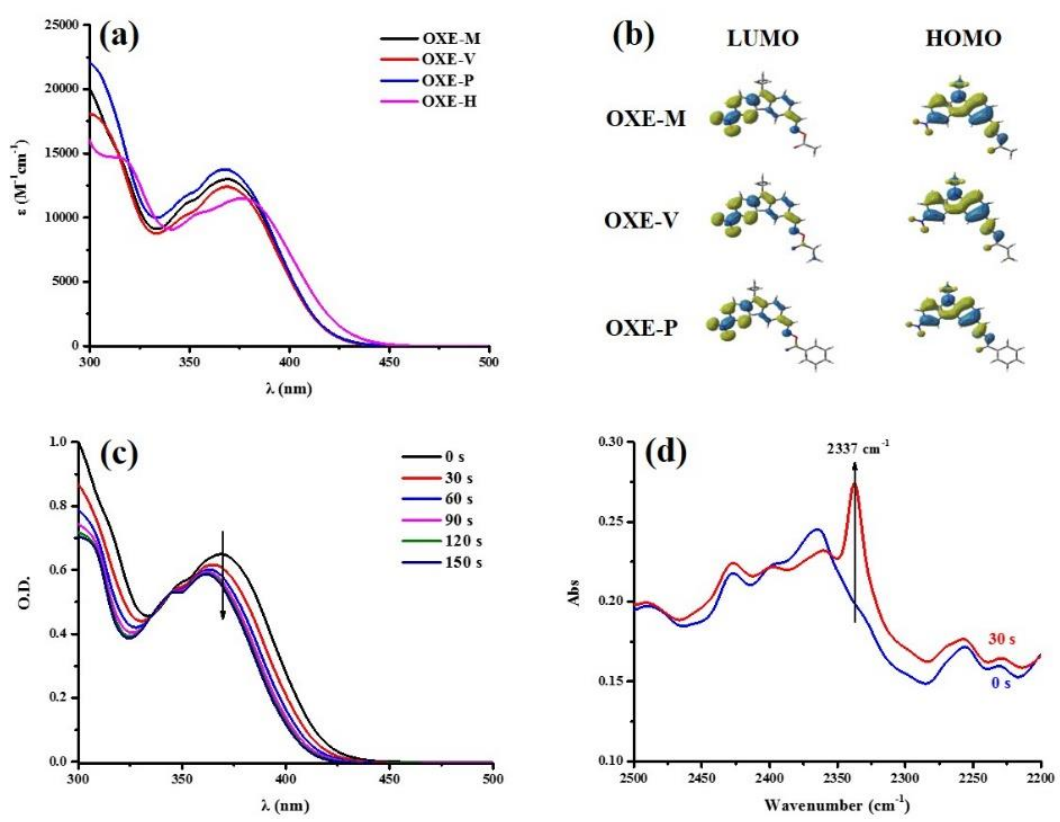

Figure 1. (a) UV-visible absorption spectra of the different PIs in acetonitrile; (b) LUMO and HOMO of the three OXEs based on TD-DFT calculations; (c) Steady state photolysis of OXE-M in acetonitrile; (d) The detection of $\mathrm{CO}_{2}$ for OXE-M system.

In addition, the fluorescence lifetime of the three OXEs were measured (See Figure S3). The fluorescence lifetime values exhibited very short times ( $<<1.4 \mathrm{~ns})$. This short lifetime being also observed for OXE-H (without possible cleavage process), this property is an intrinsic parameter of the nitro-carbazole oxime chromophore. The singlet excited state energy levels $\left(E_{S 1}\right)$ were determined from the crossing point of absorption and fluorescence spectra (Figure S4 and Table 1). Triplet state energy ( $\left.\mathrm{E}_{\mathrm{T}}\right)$ and N-O bond energy of the three OXEs were calculated (Table 1). The N-O bond energy of OXE-V $\left(49.50 \mathrm{kcal} \mathrm{mol}^{-1}\right)$ is higher than that of OXE-M (48.62 kcal mol-1) and OXE-P (48.07 kcal mol $\left.{ }^{-1}\right)$. Markedly, the calculated triplet state energy levels are higher for OXE-M, OXE-V, OXE-P than their N-O bond dissociation energy (See Table 1) suggesting a favorable cleavage from triplet state. The enthalpies of the cleavage process from $\mathrm{T}_{1}\left(\Delta \mathrm{H}_{\text {cleavage } \mathrm{T} 1}=\mathrm{BDE}(\mathrm{N}-\mathrm{O})-\mathrm{E}_{\mathrm{T}}\right)$ are all favorable $($ Table 1$)$. This is in full agreement with laser flash photolysis data which does not revealed the presence of long-lived triplet states (See Figure S5). From this work, triplet state cleavage is suspected but singlet state cleavage cannot be completely ruled out i.e. also 
energetically favorable $\left(\Delta \mathrm{H}_{\text {cleavage } \mathrm{S} 1}=\mathrm{BDE}(\mathrm{N}-\mathrm{O})-\mathrm{E}_{\mathrm{S} 1}\right)$.

Table 1. Some parameters of the PIs.

\begin{tabular}{ccccccc}
\hline PI & $\begin{array}{c}\mathrm{N}-\mathrm{O} \text { BDE } \\
/ \mathrm{kcal} \mathrm{mol}^{-1}\end{array}$ & $\begin{array}{c}\mathrm{E}_{\mathrm{S} 1} \\
/ \mathrm{kcal} \mathrm{mol}^{-1}\end{array}$ & $\begin{array}{c}\Delta \mathrm{H}_{\text {cleavage S1 }}{ }^{\mathbf{a}} \\
/ \mathrm{kcal} \mathrm{mol}^{-1}\end{array}$ & $\begin{array}{c}\mathrm{E}_{\mathrm{T}} \\
/ \mathrm{kcal} \mathrm{mol}^{-1}\end{array}$ & $\begin{array}{c}\Delta \mathrm{H}_{\text {cleavage T1 }} \mathbf{b} \\
/ \mathrm{kcal} \mathrm{mol}^{-1}\end{array}$ & $\begin{array}{c}\text { Thermal initiators } \\
\text { behavior: } \\
\text { Onset temperature } \\
\left({ }^{\circ} \mathrm{C}\right) / \text { acrylate } \\
\text { conversion }(\%)\end{array}$ \\
\hline OXE-M & 48.62 & 66.21 & -17.59 & 52.65 & -4.03 & $113 / 39.3$ \\
OXE-V & 49.50 & 66.28 & -16.78 & 52.66 & -3.16 & $157 / 27.4$ \\
OXE-P & 48.07 & 66.36 & -18.29 & 53.36 & -5.29 & $158 / 35.2$ \\
\hline
\end{tabular}

a: $\Delta \mathrm{H}_{\text {cleavage }} \mathrm{S} 1=\mathrm{BDE}(\mathrm{N}-\mathrm{O})-\mathrm{E}_{\mathrm{S} 1}$

b: $\Delta \mathrm{H}_{\text {cleavage } \mathrm{T} 1}=\mathrm{BDE}(\mathrm{N}-\mathrm{O})-\mathrm{E}_{\mathrm{T}}$

The photoinitiation ability of these OXEs in acrylate monomer trimethylolpropane triacrylate (TMPTA) was investigated in laminate (to avoid the $\mathrm{O}_{2}$ inhibition) by RTFTIR. The conversion of acrylate functions of TMPTA was continuously followed at about $1630 \mathrm{~cm}^{-1}$. A LED@405 nm was used as the light source for this study and the light intensity was about $40 \mathrm{~mW} \mathrm{~cm}{ }^{-2}$. The visible PI TPO was selected as a reference compound as this molecule is a benchmark Type I PI. The photopolymerization profiles of TMPTA are shown in Figure 2. The photoinitiation ability of OXE-H was inefficient due to the absence of the oxime ester group (no $\mathrm{CO}_{2}$ released by the cleavage processsee above). Interestingly, the three selected nitro-based OXEs demonstrated good performance where fast polymerization rates and high final function conversions were observed. Markedly, the OXE-M-based system exhibited a higher final function conversion $(\mathrm{FC}=69 \%)$ than the TPO system $(\mathrm{FC}=65 \%)$. In addition, the final function conversions are favorable for OXE-V system $(\mathrm{FC}=57 \%)$ and OXE-P system $(\mathrm{FC}=$ $61 \%$ ). The substituents R (methyl, vinyl, phenyl) on the terminal moieties of oxime ester group make a difference on the final acrylate function conversion but not really on the polymerization rates. OXE-M has a better performance than OXE-P which could be ascribed to the smaller steric hindrance for methyl radical than phenyl radical. A stabilization of the phenyl radical by delocalization of the charge on the aromatic structure can also be suggested as adversely affecting the reactivity of the phenyl 
radicals. A lower function conversion was obtained for OXE-V system under the same irradiation condition probably indicating a copolymerization with the acrylate network.

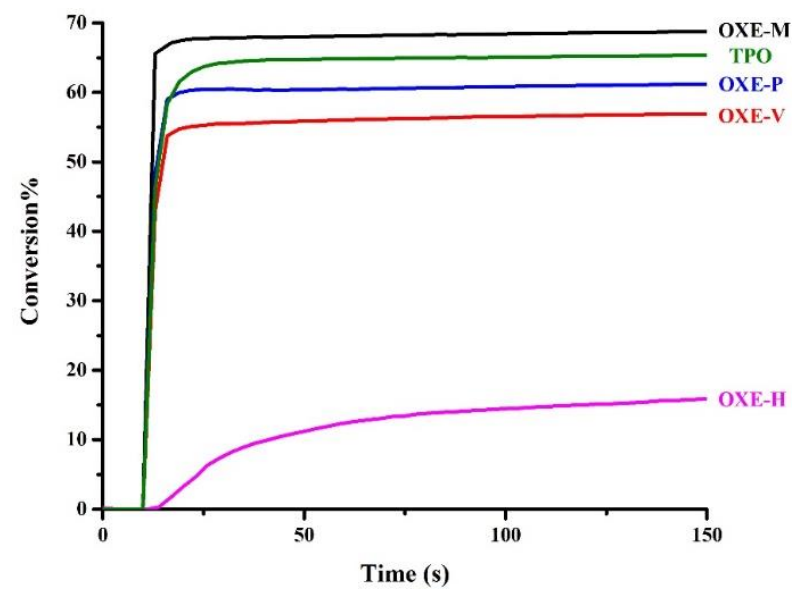

Figure 2. Photopolymerization profiles of TMPTA $(\sim 25 \mu \mathrm{m})$ under LED@405 nm irradiation in the presence of PIs $\left(2 \times 10^{-5} \mathrm{~mol} / \mathrm{g}\right.$ TMPTA $)$. The irradiation starts at $\mathrm{t}=$ $10 \mathrm{~s}$.

According to the above results, the proposed chemical mechanisms of OXEs are illustrated in Scheme 2. Under LED@405 nm irradiation, the OXEs molecules are promoted from their ground states to their excited states and then the cleavage of $\mathrm{N}-\mathrm{O}$ bond can occur, generating iminyl and acyloxy radicals. While the iminyl radical is ineffective for free polymerization, after decarboxylation, acyloxy radical generates, after $\mathrm{CO}_{2}$ release, a highly active free radical $\left(\mathrm{R}^{*}\right)$ which is responsible for the polymerization of acrylate monomers.

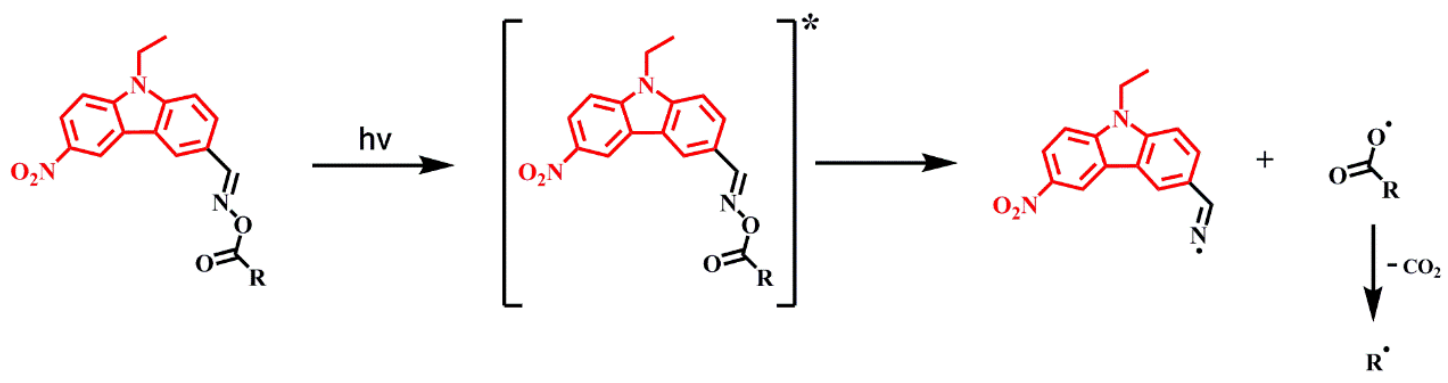

Scheme 2. Proposed photochemical mechanisms for OXEs in this study.

The photopolymerization of OXE-M (1 wt $\%)$ in TMPTA was applied in direct laser 
write and 3D printing. The direct laser write experiments were carried out upon irradiation with a laser diode at $405 \mathrm{~nm}$ under air. The letter pattern "OXE" and the characterization by numerical optical microscopy are given in Figure $3 \mathrm{a}$ and $3 \mathrm{~b}$. The thickness achieved by the printed pattern letter is around $2100 \mu \mathrm{m}$ and a good spatial resolution can be observed. In addition, as shown in Figure 3c, the square frame was obtained through the 3D printer with a LED@405 nm. Indeed, the excellent performance of OXE-M in photopolymerization makes it an ideal candidate for laser write and 3D printing.

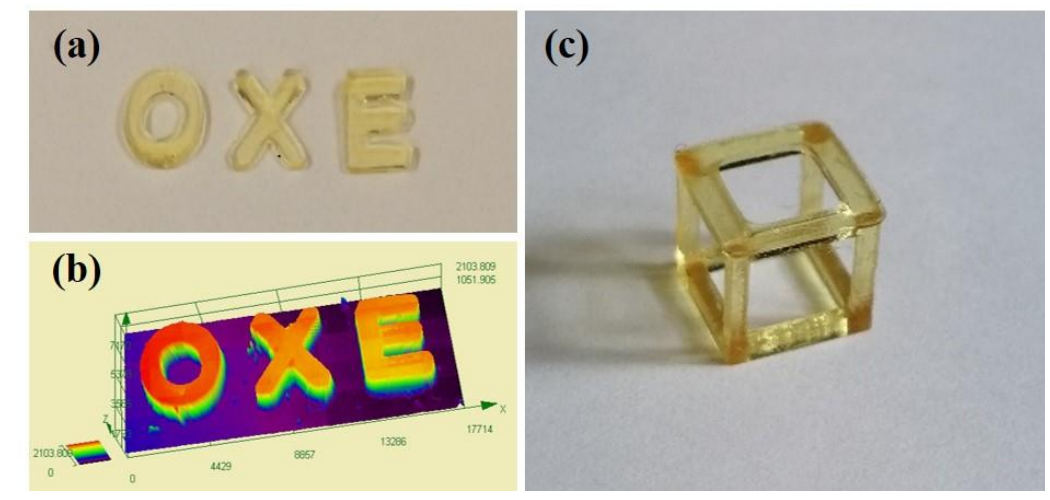

Figure 3. (a) The letter pattern "OXE" obtained by direct laser write; (b) Characterization of the letter pattern "OXE"; (c) 3D printed object of square frame (7 $\times 7 \times 7 \mathrm{~mm})$.

Besides the photoinitiation behavior, thermal stability and thermal initiating ability of oxime ester PIs in monomers is also important. The thermal initiation/stability of these formulations were tested by DSC in the dark (Figure S6) and the onset temperatures are given in Table 1. The final acrylate conversion (FC) can also be evaluated from these experiments using the heat released and the reaction heat for acrylate double bond polymerization $\left(\Delta \mathrm{H}_{\text {theory }}=78.61 \mathrm{~kJ} / \mathrm{mol}\right.$; leading to $844.5 \mathrm{~J} / \mathrm{g}$ for $100 \%$ of acrylate function conversion in TMPTA) $(\mathrm{FC}=($ heat relased $/ \mathrm{g}) / 844.5){ }^{28}$ OXE-M have the lowest onset temperature and it starts to decompose in monomers at $113^{\circ} \mathrm{C}$ which can satisfy the application demands normally. Markedly, OXE-M, V, P exhibited a dual photo/thermal initiator behavior. For OXE-V and OXE-P, a better thermal stability is found, the polymerization temperature being $>150^{\circ} \mathrm{C}$. The thermal 
polymerization behavior of OXE-M was also proved by heating. The formulation was put in oven at $150{ }^{\circ} \mathrm{C}$ for $30 \mathrm{~min}$ and the solid polymer was observed, while pure TMPTA was still liquid (Figure S7).

Due to the thermal initiation behaviors, OXE-M could be applied as dual photo/thermal initiator. Opaque feature of carbon fiber makes it difficult for light transmission, so thermal curing or dual photo/thermal curing are used to prepare carbon fiber composites. As shown in Figure 4, carbon fiber composites were produced successfully using OXE-M/TMPTA system (OXE-M, $1 \mathrm{wt} \%$ ). After preparation of prepregs (See Figure 4a), they were irradiated using LED@395 nm to initiate the photopolymerization of TMPTA in surface (Figure 4b). The tack-free surface of prepregs is helpful for transportation or storage. Then, the prepregs were heated at $150^{\circ} \mathrm{C}$ in oven for $30 \mathrm{~min}$ to induce the polymerization of TMPTA in depth. Fully cured carbon fiber composites were obtained (See Figure 4c). The surface and inside of the composites are hard and non-sticky.

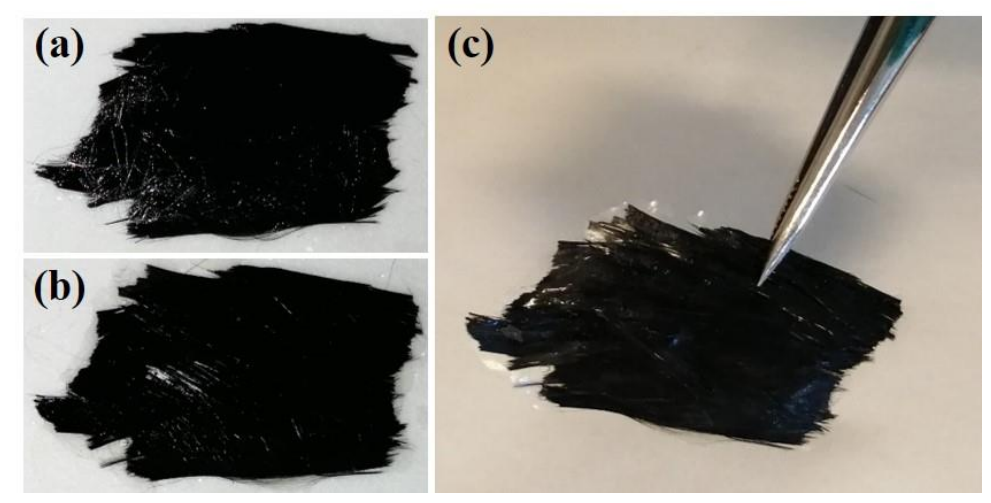

Figure 4. (a) Prepregs with resin/carbon fiber (50/50, wt $\% / w t \%)$; (b) Surface cured prepregs; (c) Carbon fiber composite.

\section{Conclusion}

In this study, three original oxime ester PIs (OXE-M, OXE-V and OXE-P) were proposed for LED photopolymerization. Due to the presence of the nitro-carbazole chromophore, good light absorption properties were obtained for these oxime ester PIs at $405 \mathrm{~nm}$. Steady state photolysis experiments and the detection of $\mathrm{CO}_{2}$ were carried 
out in order to investigate the proposed chemical mechanisms. Under irradiation, the cleavage of $\mathrm{N}-\mathrm{O}$ bond and the decarboxylation reaction occur to generate an active free radical which can initiate the polymerization of acrylate monomers. High function conversions were obtained in the presence of these oxime ester PIs in TMPTA under LED@405 nm irradiation. Notably, OXE-M was more effective than the benchmark Type I PI TPO. Meanwhile, the effect of substituent on terminal moieties of oxime ester group was discussed. The free radical polymerization in the presence of OXE-M was applied in direct laser write and 3D printing experiments. Both a well resolved pattern and a 3D objects were obtained successfully. In addition, the good thermal stability and thermal initiator behavior is found for these OXEs. Markedly, OXE-M based system exhibited an interesting dual photo/thermal curing ability that can be used in composite preparation.

\section{Acknowledgements}

This research project is supported by China Scholarship Council (CSC N0. 201906880009).

\section{Conflict of Interest}

The authors declare no conflict of interest. 


\section{Reference}

(1) Xiao, P.; Zhang, J.; Dumur, F.; Tehfe, M. A.; Morlet-Savary, F.; Graff, B.; Gigmes, D.; Fouassier, J. P.; Lalevée, J. Visible light sensitive photoinitiating systems: Recent progress in cationic and radical photopolymerization reactions under soft conditions. Progress in Polymer Science 2015, 41, 32-66.

(2) Yagci, Y.; Jockusch, S.; Turro, N. J. Photoinitiated Polymerization: Advances, Challenges, and Opportunities. Macromolecules 2010, 43, 6245-6260.

(3) Yao, M.; Gao, P.; Zhao, H.; Nie, J.; He, Y. Photo-patternable F-containing acrylic copolymers as passivation materials. Materials Chemistry and Physics 2020, 253, 123404.

(4) Li, J.; Hao, Y.; Zhong, M.; Tang, L.; Nie, J.; Zhu, X. Synthesis of furan derivative as LED light photoinitiator: One-pot, low usage, photobleaching for light color 3D printing. Dyes and Pigments 2019, $165,467-473$

(5) Nguyen, A. K.; Narayan, R. J. Two-photon polymerization for biological applications. Materials Today 2017, 20, 314-322.

(6) Zhang, Y.; Xu, Y.; Simon-Masseron, A.; Lalevée, J. Radical photoinitiation with LEDs and applications in the 3D printing of composites. Chemical Society Reviews 2021, DOI : 10.1039/D0CS01411G

(7) Zhang, Y.; Josien, L.; Salomon, J.-P.; Simon-Masseron, A.; Lalevée, J. Photopolymerization of Zeolite/Polymer-Based Composites: toward 3D and 4D Printing Applications. ACS Applied Polymer Materials 2021, 3, 400-409.

(8) Schmitz, C.; Pang, Y.; Gülz, A.; Gläser, M.; Horst, J.; Jäger, M.; Strehmel, B. New High-Power LEDs Open Photochemistry for Near-Infrared-Sensitized Radical and Cationic Photopolymerization. Angewandte Chemie International Edition 2019, 58, 4400-4404.

(9) Chen, H.; Noirbent, G.; Sun, K.; Brunel, D.; Gigmes, D.; Morlet-Savary, F.; Zhang, Y.; Liu, S.; Xiao, P.; Dumur, F.; Lalevée, J. Photoinitiators derived from natural product scaffolds: monochalcones in threecomponent photoinitiating systems and their applications in 3D printing. Polymer Chemistry 2020, 11, 4647-4659.

(10) Liu, S.; Brunel, D.; Sun, K.; Xu, Y.; Morlet-Savary, F.; Graff, B.; Xiao, P.; Dumur, F.; Lalevée, J. A monocomponent bifunctional benzophenone-carbazole type II photoinitiator for LED photoinitiating systems. Polymer Chemistry 2020, 11, 3551-3556.

(11) Cınar, S. A.; Guven, M. N.; Eren, T. N.; Cesur, B.; Aleksanyan, M.; Dedeoglu, B.; Okte, N.; Aviyente, V.; Morlet-Savary, F.; Lalevée, J.; Avci, D. Structure-reactivity relationships of novel monomeric photoinitiators. Journal of Photochemistry and Photobiology A: Chemistry 2016, 329, 77-87.

(12) Oesterreicher, A.; Roth, M.; Hennen, D.; Mostegel, F. H.; Edler, M.; Kappaun, S.; Griesser, T. Low migration type I photoinitiators for biocompatible thiol-ene formulations. European Polymer Journal 2017, 88, 393-402.

(13) Liu, S.; Brunel, D.; Noirbent, G.; Mau, A.; Chen, H.; Morlet-Savary, F.; Graff, B.; Gigmes, D.; Xiao, P.; Dumur, F.; Lalevée, J. New multifunctional benzophenone-based photoinitiators with high migration stability and their applications in 3D printing. Materials Chemistry Frontiers 2021, 5, 1982-1994.

(14) Khudyakov, I. V. Fast photopolymerization of acrylate coatings: Achievements and problems. Progress in Organic Coatings 2018, 121, 151-159.

(15) Liu, S.; Brunel, D.; Sun, K.; Zhang, Y.; Chen, H.; Xiao, P.; Dumur, F.; Lalevée, J. Novel Photoinitiators Based on Benzophenone-Triphenylamine Hybrid Structure for LED Photopolymerization. Macromolecular Rapid Communications 2020, 41, 2000460.

(16) Sun, K.; Xu, Y.; Dumur, F.; Morlet-Savary, F.; Chen, H.; Dietlin, C.; Graff, B.; Lalevée, J.; Xiao, P. In silico rational design by molecular modeling of new ketones as photoinitiators in three-component 
photoinitiating systems: application in 3D printing. polym. chem 2020, 11, 2230-2242.

(17) Noirbent, G.; Dumur, F. Recent advances on naphthalic anhydrides and 1,8-naphthalimide-based photoinitiators of polymerization. European Polymer Journal 2020, 132, 109702.

(18) Li, Z.; Zou, X.; Zhu, G.; Liu, X.; Liu, R. Coumarin-Based Oxime Esters: Photobleachable and Versatile Unimolecular Initiators for Acrylate and Thiol-Based Click Photopolymerization under Visible LightEmitting Diode Light Irradiation. ACS Applied Materials \& Interfaces 2018, 10, 16113-16123.

(19) Qiu, W.; Li, M.; Yang, Y.; Li, Z.; Dietliker, K. Cleavable coumarin-based oxime esters with terminal heterocyclic moieties: photobleachable initiators for deep photocuring under visible LED light irradiation. Polymer Chemistry 2020, 11, 1356-1363.

(20) Ma, X.; Cao, D.; Fu, H.; You, J.; Gu, R.; Fan, B.; Nie, J.; Wang, T. Multicomponent photoinitiating systems containing arylamino oxime ester for visible light photopolymerization. Progress in Organic Coatings 2019, 135, 517-524.

(21) Xu, J.; Ma, G.; Wang, K.; Gu, J.; Jiang, S.; Nie, J. Synthesis and photopolymerization kinetics of oxime ester photoinitiators. Journal of Applied Polymer Science 2012, 123, 725-731.

(22) Burget, D.; Fouassier, J. P.; Amat-Guerri, F.; Mallavia, R.; Sastre, R. Enhanced activity as polymerization photoinitiators of Rose Bengal and Eosin esters with an O-benzoyl- $\alpha$-oxooxime group: The role of the excited state reactivity. Acta Polymerica 1999, 50, 337-346.

(23) Fast, D. E.; Lauer, A.; Menzel, J. P.; Kelterer, A.-M.; Gescheidt, G.; Barner-Kowollik, C. WavelengthDependent Photochemistry of Oxime Ester Photoinitiators. Macromolecules 2017, 50, 1815-1823.

(24) Wang, W.; Jin, M.; Pan, H.; Wan, D. Phenylthioether thiophene-based oxime esters as novel photoinitiators for free radical photopolymerization under LED irradiation wavelength exposure. Progress in Organic Coatings 2021, 151, 106019.

(25) Offenloch, J. T.; Blasco, E.; Bastian, S.; Barner-Kowollik, C.; Mutlu, H. Self-reporting visible lightinduced polymer chain collapse. Polymer Chemistry 2019, 10, 4513-4518.

(26) Schultz, C. P.; Eysel, H. H.; Mantsch, H. H.; Jackson, M. Carbon Dioxide in Tissues, Cells, and Biological Fluids Detected by FTIR Spectroscopy. The Journal of Physical Chemistry 1996, 100, 6845-6848.

(27) Kumar, J.; D'Souza, S. F. Preparation of PVA membrane for immobilization of GOD for glucose biosensor. Talanta 2008, 75, 183-188.

(28) McCurdy, K. G.; Laidler, K. J. Thermochemical studies of some acrylate and methacrylate polymerizations in emulsion systems. Canadian Journal of Chemistry 1964, 42, 818-824. 
TOC graphic:

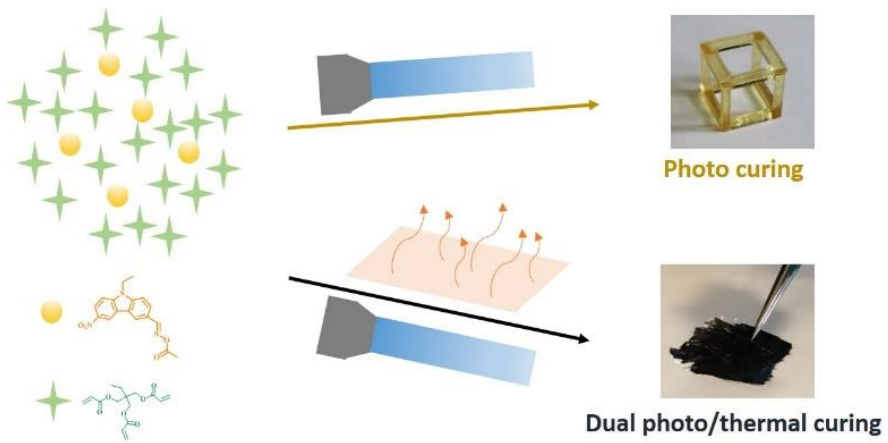

